\title{
Sexual selection and intra-female competition in the green poison-dart frog, Dendrobates auratus
}

\author{
KYLE SUMMERS \\ Museum of Zoology, University of Michigan, Ann Arbor, MI 48109, U.S.A. \\ and \\ Smithsonian Tropical Research Institute, P.O. Box 2072, Balboa, Panama
}

\begin{abstract}
Observations on the mating and parental behaviour of the green poison-dart frog were used to test two hypotheses for the function of female-female competition in this species. The hypothesis that females compete to monopolize as many mates as possible was not supported because: (1) male territoriality was associated with competition for females; (2) intra-female competition for mates was not more common or intense than intra-male competition; (3) females were more selective about mating than were males; (4) estimated offspring production by individual females did not exceed the parental capacity of a single male. The hypothesis that females compete to monopolize the parental care of particular males was consistent with observations that: (1) females competed for males, but were more selective about mating than were males; (2) females remained near particular males and attempted to keep other females from mating with those males; (3) females may have used courtship to prevent males from mating with other females. Both hypotheses were consistent with evidence that: (1) females are large compared with males in $D$. auratus, relative to closely related species with low male parental investment; (2) females destroyed the eggs of other females when they located them.
\end{abstract}

Williams (1966) and Trivers (1972) argued that relative parental investment is the primary determinant of the mating strategies of males and females in many species of animals. They argued that the sex that supplies the larger share of parental investment (investment in particular offspring that limits the parent's potential to produce other offspring) will become a limiting resource for which members of the other sex compete. Females provide most parental investment in most species that have been studied, and intra-male competition exceeds intra-female competition for mates, whereas females are often selective compared with males. In species where male parental investment significantly exceeds that of females, sex role reversal should occur, that is, females compete for a limited number of available males and males are choosier than females about whom they mate with. Citing observations of males performing parental care (Eaton 1941) and of more than one female following a single calling male (Dunn 1941), Trivers (1972) suggested that sex role reversal might occur in the green poison dart frog. Wells (1978) studied D. auratus in the field and in captivity in Panama, and suggested that his observations were consistent with the hypothesis of sex role reversal; that small clutch size and large time investment by males in parental care may have caused receptive males to become rare compared with receptive females, causing female-female competition and female courtship of males. This hypothesis will be referred to as the sex role reversal hypothesis.

Parental investment by males can cause competition for mates among females, even if male parental investment does not exceed female parental investment. Variance in the quality or quantity of parental care provided by males may lead to sclection for femalc competition for those males able to provide the highest quality parental care (Wittenberger 1979; Petrie 1983, 1986). Female competition for males should also be favoured by selection if the quality or quantity of parental care provided by any particular male declines as his number of mates increases (Yasukawa \& Searcy 1982; Halliday 1983; Hrdy \& Williams 1983). Males may achieve higher reproductive success by being polygynous even if the quality or quantity of parental care they can provide per offspring declines with increasing offspring number. For any particular female the quality of a male would decrease as the number of other females mating with that male increased. This is analogous to the effect of decline in territory quality in the polygyny threshold model (Orians 1969). In this situation 
females should attempt to ensure that their mate(s) mate with as few other females as possible. This will be referred to as the parental quality hypothesis. The purpose of this paper is to examine the extent to which the behaviour of $D$. auratus accords with predictions derived from these two hypotheses.

The following predictions are derived from the sex role reversal hypothesis. (1) Males will not be territorial in order to acquire mating opportunities, because receptive females (defined as females ready to ovipost) should be abundant relative to receptive males (defined as males who are able to fertilize and care for eggs). (2) Intrasexual competition for mates will be more common and intense among females than among males, because males will be limiting as mates. (3) Males will be more selective about mating than females, because males invest more per mating. (4) A female will produce eggs at a rate that exceeds the capacity of a single male to care for them; this creates the lack of receptive males.

The following predictions are derived from the parental quality hypothesis. (1) Females will compete for males, but intra-female aggression will not necessarily be more common or intense than intramale competition. (2) Females will be more selective than males, because females invest more per mating. (3) Females will remain near the territories of particular males and attempt to prevent other females from mating with those males, in order to prevent them from investing in the offspring of other females. (4) Females will attempt to manipulate males to prevent them from mating with other females. Because males profit by mating with many females, they should attempt to court and mate with any female that indicates receptivity. This makes males susceptible to manipulation by females.

Both the sex role reversal and the parental quality hypothesis predict the following. (1) Females will be large relative to males, compared with females of closely related species in which male parental investment is low. This prediction assumes that large size correlates with fighting ability (Shine 1979; but see Halliday \& Verrell 1986), and that the age structures of the species being compared are similar. (2) Females will destroy the eggs of other females when they find them. The sex role reversal hypothesis predicts that females will destroy eggs in order to make the parental male receptive. The parental quality hypothesis predicts that females will destroy eggs in order to prevent her mate from investing in the eggs of other females.

Dendrobates auratus is a member of the Dendrobatidae, a family of diurnal, terrestrial frogs found in northern South America and southern Central America. All members of the genus Dendrobates that have been studied are highly toxic (Myers \& Daly 1976). Field and laboratory studies of congeners have revealed complex patterns of courtship, aggression and parental care (Senfft 1936; Eaton 1941; Breder 1946; Duellman 1966; Crump 1972; Bunnell 1973; Silverstone 1973, 1975; Wells 1978, 1980, 1981; Weygoldt 1980; Zimmermann \& Zimmermann 1981).

Intrasexual aggression, consisting of grappling, clasping, pushing and ramming, occurs in both sexes of D. auratus (Wells 1978). Females have been observed competing for calling males in the laboratory (Senfft 1936; Zimmermann 1974; Grow 1977; Wells 1978). Courtship is prolonged in this species, ranging from less than an hour to $8 \mathrm{~h}$, during which the male leads the female in and out of the leaf litter (Wells 1978). Eggs are deposited in the leaf litter after which the male and the female leave the site. Parental care is performed by the male and consists of egg attendance (which involves jostling and moistening the eggs), looking for tadpole deposition sites (usually small pools of water in the branches of trees), and carrying tadpoles to such sites (Senfft 1936; Eaton 1941; Breder 1946; Wells 1978)

\section{METHODS}

Data were obtained from June through August of 1985 and 1986. Field observations were made 4 or 5 days a week, between 0700 and 1800 hours, in a seasonal tropical forest on Taboga Island, Republic of Panama. The main study site in 1985 was a grid measuring $16 \times 22 \mathrm{~m}$ located next to a trail in Taboga's largest valley. The study site in 1986 was a grid measuring $12 \times 20 \mathrm{~m}$ located $40 \mathrm{~m}$ southwest from the 1985 study site. Both grids were marked with red flags at 2-m intervals.

Frogs were marked individually by toe-clipping. Their dorsal patterns were drawn on identification cards. These patterns were individually distinctive, which made recognition easy. Each frog was weighed and measured (snout-vent length). Because frogs in this species spend a considerable 
amount of time under the leaf litter, I was not able to assign times randomly to watch particular individuals. Hence, individuals observed on an opportunistic basis during patrols of the study site were followed and pertinent behaviour was recorded. Observations on single individuals were recorded continuously for at least $1 \mathrm{~min}$. During interactions between two or more individuals I recorded inter-individual behaviour sequences (Altmann 1974). The criterion used to classify the terminations of male-female encounters (Table I) were as follows. $\Lambda$ female was considered to have rejected a male if she courted him and then moved away from or did not respond to him while he continucd to call to her, follow or stroke her. A female was considered to have ignored a male if she moved away or did not respond when he approached and called to her, followed or stroked her. The reciprocal occurrences were taken as evidence for a male rejecting or ignoring a female, respectively. The 'Temale Chased' category refers to cases in which a female approaching or courting with a male was driven away by another female. The 'Separate' category refers to instances where the male and female separated without clear rejection.

An effort was made to patrol the study site and record the locations and behaviour of all individuals observed on an hourly basis, although this was not always possible due to the necessity of observing individuals closely during certain types of behaviour (e.g. tadpole transportation). Calls were recorded and played back with a minicassete recorder.

Size dimorphism comparisons between species were done with model 1 two-way ANOVAs using snout-vent length as the dependent variable, with two levels for factor A (species) and two levels for factor B (sex). Size data on D. auratus were obtained on Taboga Island. Data on D. leucomelas were obtained at Guri Dam, Venezuela. Data on $D$. pumilio were obtained from museum specimens at the University of Michigan Museum of Zoology. Data on D. histrionicus and D. lehmanni were provided by C. Myers at the American Museum of Natural History. The skewness and kurtosis of the size data were examined to ensure that the assumptions of normality required by the parametric test were not violated. Statistical analyses were performed with MIDAS, a statistics program created by the Statistical Research Laboratory at the
University of Michigan, and with Statview, a microcomputer statistics package. Data are give for both years when available.

\section{RESULTS}

\section{Territoriality}

Seven males were observed in the study site consistently throughout the 1985 season ( $\bar{X} \pm \mathrm{SD}=72 \pm 13 \%$ of the study days) and 1986 season (seven different males; $\bar{X} \pm \mathrm{SD}=92 \pm 6 \%$ ). These males were usually (i.e. $90 \%$ of observations) observed within small areas on the study site $\left(\bar{X} \pm \mathrm{SD}=3.15 \pm 0.70 \mathrm{~m}^{2}\right)$. Transient males were observed passing through the study sites frequently. These males usually carried tadpoles and did not court with females.

Males frequently faced toward and called to each other from within the areas they were usually observed in. Calls were played to nine males in their areas in $1985(N=141)$. Males responded to calls in $99 \%$ of the trails. Response consisted of facing the recorder and calling back. Males usually moved toward the recorder as well. Conversely, males outside their areas did not call back and either moved away or remained motionless (1985, $N=5$; $1986, N=28$ ). On several occasions males returned to their own areas and then called $(1985, N=1$; 1986, $N=4$ ).

Males fought with other males at places of area overlap (1985, $N=18 ; 1986, N=32)$. These encounters always ended with each male moving toward the centre of his area and calling for several min. Males passing through another male's area were sometimes called to, chased and attacked by the resident male $(1985, N=11 ; 1986, N=12)$. Aggressive interactions between males usually did not involve direct competition for females; in most of the interactions no female was in the vicinity (within $1 \mathrm{~m}$ ) of the fighting males $(79 \%$ in 1985 , $91 \%$ in 1986).

Fourteen females were seen consistently over a period of at least a month on the study site in 1986. The average percentage of area overlap was higher between female areas $(\bar{X} \pm \mathrm{SD}=13 \cdot 6 \pm 23 \cdot 8 \%$, $N=168)$ than between male areas $(\bar{X} \pm \mathrm{SD}=$ $3.6 \pm 9.7 \%, \quad N=72, \quad$ Mann-Whitney $U$-test, $P<0.0002)$. Nine other females who came into the study site and stayed temporarily ( $1-2$ weeks) were 


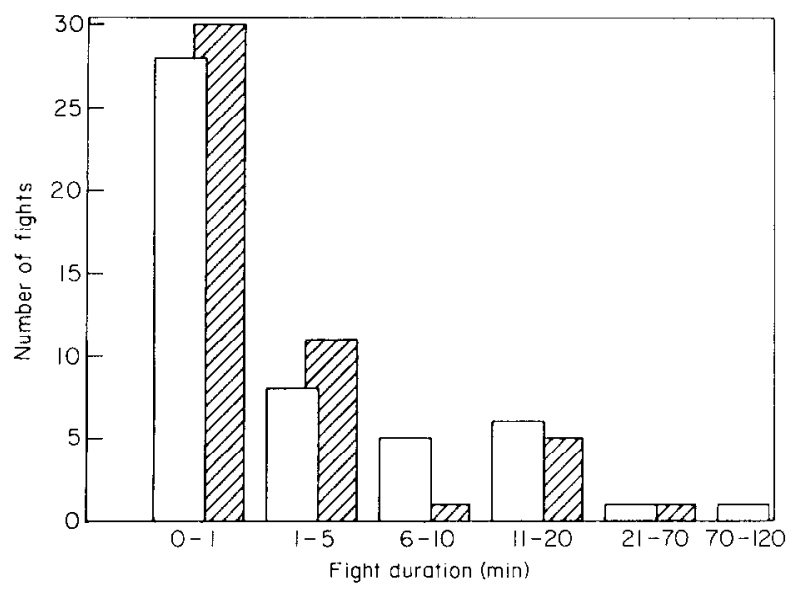

Figure 1. Distributions of aggressive bout lengths for males ( $\square$ ) and females ( $\square$ ) in 1986.

marked. These and other (unmarked) females were observed courting with males in the study area.

\section{Aggression}

Aggressive interactions occurred between females in 1985 and $1986(N=66)$. In $97 \%$ of these interactions a male was observed near the females (within $50 \mathrm{~cm}$ ), following and calling at them. Females were observed sitting or feeding near each other without aggression in the absence of calling males. In 1985, two females were observed in the area occupied by a particular male for over 2 weeks. These females each courted the male in their area repeatedly during this period, and both wrestled with and chased other females that approached the male (two occasions each). One of these females is known to have mated with the male she remained near. In 1986, eight females were responsible for at least $83 \%$ of the aggressive interactions (some observations occurred before all females werc marked). Four of these females were usually observed in the territory of a particular male throughout the study (10 wecks). The other four aggressive females ranged more widely, but were observed to remain in or near a particular male's territory for several weeks at a time during the study. These eight females were frequently observed courting with the male in their area and attacking other fcmalcs that approached the male $(N=41)$. Six of these females are known to have mated with the male in their area at least once during the study.

Males and females appeared to fight in the same manner. The two frogs would approach each other, grapple with their forelegs, and then try to move round to the back of the other frog. This often resulted in both frogs moving rapidly in a circle. If one frog got behind another it would clasp it around the centre of the body with the forelegs and then attempt to push the other by extending the rear legs and bringing the weight of its body to bear on the other's dorsum. Fighting also involved jumping on, charging and ramming of the opponent. During some aggressive interactions one frog was clearly dominant to the other, which would try to escape. In 1985, 17 female and 34 male aggressive interactions werc observed. In 1986, 49 female and 49 male aggressive interactions were observed. The number of aggressive bouts per time observed did not differ significantly between males and females in $1986\left(\chi^{2}\right.$ test, $\left.P>0 \cdot 1\right)$. The distributions of aggressive bout lengths in 1986 are shown in Fig. 1. Female fights were not significantly longer than those of males in 1985 (Mann-Whitney $U$-test, $N=51, P>0.05$ ) or 1986 (Mann-Whitney $U$-test, $N=98, P>0.05$ ). Bouts were described as being intense if both individuals involved appeared to be fighting back for at least 1 min (rather than one individual being obviously dominant). Intense bouts were more common for males than for females in 1985 (12/34 versus $4 / 17$, chi-squared test, $P<0.05)$ and in $1986(20 / 49$ versus $8 / 49$, chisquared test, $P<0.025$ ). 
Table I. Observed totals (percentages) of male-female encounter terminations

\begin{tabular}{lcc}
\hline & 1986 & 1985 \\
\hline Female: rejects & $62(33)$ & $18(30)$ \\
Female: ignores & $45(24)$ & $14(23)$ \\
Female: chased & $40(21)$ & $11(18)$ \\
Oviposit & $30(16)$ & $8(13)$ \\
Male: ignores & $6(3)$ & $1(2)$ \\
Separate & $6(3)$ & $8(13)$ \\
\hline
\end{tabular}

Behavioural categories are described in the Methods section.

\section{Selectivity}

Two measures of choosiness were investigated; rate of initation of tactile interaction during courtship and frequency of rejection in male-female encounters. Sequences of tactile interaction between males and females were recorded during courtships in 1985 and 1986. Females were significantly more active than males as measured by the rate of tactile courtship (rate at which one sex stroked, nudged, climbed on or jumped on the other; Wilcoxon signed-ranks test; 1985: $N=24$, $P<0.01 ; 1986: N=19, P<0.01)$. Table I shows the terminations of male-female encounters in both years. Females rejected or ignored males more commonly than males rejected or ignored females in 1985 ( 32 versus 2, chi-squared test, $P<0.05$ ) and 1986 (107 versus 6 , chi-squared test, $P<0.0001$ ).

\section{Parental Care}

Only males were seen performing parental care. Paternal care consisted of clutch attendance, exploration and tadpole deposition. A male would sit on on the clutch while working his legs in and out of the jelly mass. Water may have been shed on the eggs at this time, as some males were observed to sit in a pool immediately before attending a clutch. Clutch attendance averaged $43.2 \mathrm{~min}$ in 1985 $(\mathrm{SD}=12.5, N=9)$ and $19.0 \mathrm{~min}$ in $1986(\mathrm{SD}=5.0$, $N=11$ ). Egg survivorship averaged $53 \%$ $(\mathrm{SD}=43 \%, N=28 ; 1985$ and 1986 were not significantly different).

Males carried tadpoles 11 days after oviposition in $1985(\mathrm{SD}=13 \cdot 6, N=4)$ and 16 days in 1986 $(\mathrm{SD}=2 \cdot 1, N=9 \cdot 0)$. Tadpoles were carried one at a time to pools of water (usually in tree-holes, but also in squash husks, old cans and the bases of palm fronds) and deposited in them. The time taken by a male to carry a tadpole to a pool and return to his area ranged from 14 to $540 \mathrm{~min}$, and averaged 144 $\min (\mathrm{SD}=115, N=26$; data combined from 1985 and 1986 were not significantly different). The most tadpoles a male was observed to carry in 1 day was three. Males also appeared to explore for potential deposition sites. They would leave their territories and visit several tree-holes in succession, diving under the surface and moving around the perimeter of each pool. Exploration was sometimes performed immediately after the male had transported a tadpole, and sometimes independently. Exploration (independent only) ranged from 140 to 480 $\min (\bar{X} \pm \mathrm{SD}=280.6 \pm 182 \cdot 1, N=5)$.

A comparison between the rates of male and female offspring production can be made by comparing the amount of time that males put into caring for eggs and tadpoles, estimated from field observations, with the amount of time females take to produce eggs, estimated from the average rate of egg production by captive $D$. auratus females. Females in captivity produce about seven eggs per week, or about one per day. This estimate should be multiplied by the average clutch survivorship (53\%), because males do not carry dead embryos. This gives an estimate of approximately 2 days per tadpole for females. An estimate of time spent by males on caring for each tadpole can be obtained by adding the time spent on clutch attendance (divided by average clutch size), tadpole transport and exploration for deposition sites (this assumes that males explore for sites before carrying each tadpole, and hence is probably an overestimate). This gives a total of approximately $8 \mathrm{~h}$ $(31+144+281 \mathrm{~min})$ per tadpole for males. Hence males should be able to carry at least one tadpole per day. Ideally, this comparison should consider the extra amount of time males spent foraging in order to compensate for metabolic costs incurred while caring for offspring. It was not possible to measure this because it was not feasible to divide the time spent feeding by males into somatic, mating and parental effort (Alcxander \& Borgia 1979). Risk is another potential cost of male parental care, especially of carrying tadpoles into the higher branches of trecs. I obscrved several marked males fall from such high branches $(10 \mathrm{~m})$ and land on hard ground, but they suffered no apparent harm and continucd to defend territories and carry tadpoles throughout the study. 
Table II. Male and female sizes in five different species

\begin{tabular}{llcccc}
\hline \multicolumn{1}{c}{ Species } & & $\bar{X}$ & SD & $N$ & $P^{*}$ \\
\hline Paternal Care & & & & & \\
D. auratus & Male & 27.40 & 0.93 & 15 & 0.001 \\
& Female & 31.43 & 1.28 & 15 & \\
D. leucomelas & Male & 32.64 & $1 \cdot 10$ & 11 & 0.001 \\
& Female & 35.56 & 0.87 & 11 & \\
Maternal Care & & & & & \\
D. pumilio & Male & 21.43 & 1.49 & 15 & 0.785 \\
& Female & 21.57 & $1 \cdot 15$ & 15 & \\
D. histrionicus & Male & 31.06 & $1 \cdot 11$ & 15 & 0.128 \\
& Female & 30.44 & 1.05 & 15 & \\
D. lehmanni & Male & 33.51 & $1 \cdot 19$ & 15 & 0.107 \\
& Female & 32.92 & 0.70 & 15 & \\
\hline
\end{tabular}

Two-way ANOVAs were performed for every pair of species; the degree of sexual dimorphism was significantly different $(P<0.001)$ in all comparisons between species with different systems of parental care, but not between species with the same system.

* Student $t$-test of the difference between male and females.

\section{Sexual Dimorphism}

The effect of the parental care system on sexual dimorphism was examined by comparing the degree of sexual dimorphism in $D$. auratus with that of four other species in the same genus: D. leucomelas, which also has male parental care (Zimmermann \& Zimmermann 1981; personal observations), and D. pumilio, D. lehmanni and $D$. histrionicus, which have female parental care (Zimmermann \& Zimmermann 1981). Table II shows the sizes of males and females for the five species. Females were significantly larger than males in $D$. auratus and D. leucomelas, but not in the other species. The degrees of sexual dimorphism in $D$. auratus and D. leucomelas were significantly different from those in the species with female parental care, but not from each other.

\section{Oviphagy}

On two occasions, a female was observed to go under the leaf litter where the eggs of another female had been deposited. After the female had emerged and left the area the area was searched and the eggs were found to be missing from the jelly mass. On one occasion I removed a recently deposited clutch and placed it near a guarding female. The female discovered the clutch in a few hours and ate all the eggs. This behaviour has also been observed in captivity (Wells 1978).

\section{DISCUSSION}

Table III summarizes the predictions made by the two hypotheses and the relevant results. Here, I explain some of the results in more detail.

\section{Male Territoriality}

My observations on male site specificity, site tenacity and aggression indicate that $D$. auratus males are territorial on Taboga. Three hypotheses may explain male territoriality in D. auratus: (1) males are defending feeding territories, (2) males are protecting offspring, or (3) males are attempting to increase mating opportunities.

If males are defending feeding territories, they should exclude both males and non-receptive females, as they do in other dendrobatids that defend feeding territories, such as Colostethus inguinalis (Wells 1980). This prediction was not met; males were aggressive only toward other males. If males are defending feeding territories then I would expect females to do so as well, as they do in C. inguinalis (Wells 1980). This prediction was not met; females fought almost exclusively over males and were frequently observed feeding near each other without aggression.

If males are defending territories to protect their eggs and tadpoles I would expect them to guard clutches against potential egg predators. Males were observed attending their clutches, but they did not remain near the clutches for long periods. Nonreceptive females offer a potential threat to the eggs on a male's territory because they may eat eggs or larvae. However, males did not attempt to keep such females away from their territories or from the vicinity of clutches. The second hypothesis predicts that males will not engage in behaviour that poses a high risk to their offspring, yet males were observed engaging in courtship, mating and prolonged aggression while carrying tadpoles. All of these activities should pose a significant risk to the tadpole because of the possibility of it being dislodged.

The third hypothesis predicts that males will compete for females in or near their territories. Males were observed competing for a female in places of area overlap on five occasions in 1986 and 
Table III. Predictions and results relevant to the two hypotheses discussed in the text

\begin{tabular}{|c|c|c|c|}
\hline \multirow[b]{2}{*}{ Character } & \multicolumn{3}{|c|}{ Predictions } \\
\hline & Sex role reversal & Parental quality & Results \\
\hline Male territoriality & Not for mate acquisition & No prediction & For mate acquisition \\
\hline Competition for mates & $\begin{array}{l}\text { Female more frequent } \\
\text { and intense than male }\end{array}$ & Females compete & $\begin{array}{l}\text { Female and male } \\
\text { competition are equal }\end{array}$ \\
\hline Female mate guarding & No prediction & Present & Present \\
\hline Selectivity & Male higher than female & Female higher than male & Female higher than male \\
\hline Female courtship & Indicates receptivity & $\begin{array}{l}\text { Does not always } \\
\text { indicate receptivity }\end{array}$ & $\begin{array}{l}\text { Does not always } \\
\text { indicate receptivity }\end{array}$ \\
\hline Inter-clutch interval & Male longer than female & Female longer than male & Female longer than male \\
\hline Sexual dimorphism & Female larger than male & Female larger than male & Female larger than male \\
\hline Oviphagy & Present & Present & Present \\
\hline
\end{tabular}

in 1985. On each occasion one male drove the other away and then returned to court with the female in his territory, suggesting that territorial aggression is associated with competition for mates.

\section{Female mate guarding}

If females are attempting to monopolize the parental care of one or a few males, then they should remain near the territories of those males and attempt to prevent other females from mating with those males. The behaviour of eight females in 1986 and two females in 1985 was consistent with this prediction.

\section{Selectivity}

The sex role reversal hypothesis predicts that males should be more selective about mating than females. Consistent with this prediction, females were more active during courtship than males. However, evidence on intersexual encounters shows that females rejected males more commonly than the reverse, contary to the prediction of choosier males. The sex that typically invests less per offspring (and hence stands to gain more from polygamy) is the sex that can least afford to ignore or decline mating opportunities, and hence should reject such opportunities less often. Females frequently courted males and then rejected them (Table I), indicating that courtship is not a good predictor of willingness to mate in any particular male-female interaction in $D$. auratus. These considerations suggest that females are more selective than males in this system.

\section{Courtship}

Studies of other animals have presented evidence suggesting that females may use courtship to manipulate male behaviour to their own advantage (e.g. Lumpkin 1983). The data on encounter terminations show that females frequently court males and then reject them. This suggests the possibility that a female may use courtship to indicate receptivity to a male and persuade him to court with her rather than with another female. Males should be selected to determine whether or not a female is actually prepared to oviposit or not, which should produce selection on females to court males actively. On 17 occasions a guarding female attacked a female approaching the male in her vicinity, courted the male, and then rejected him 5-10 min after the other female had left, which is consistent with the hypothesis that courtship was being used to prevent the male from mating with another female.

\section{Inter-clutch Interval}

The sex role reversal hypothesis predicts that females will produce offspring at a rate that exceeds the capacity of a single male to care for them. The comparison between male and female rates of offspring production is crude, but it does suggest that the rate at which females produce eggs is unlikely to exceed the rate at which males can care for them, and that a shortage of receptive males is not likely in this species.

The high variance in the time taken by males to deposit tadpoles reflects a high variance in the distance traversed by individual males during transportation of different tadpoles, which sug- 
gests that males have the option of depositing tadpoles near their territories. Observations of several deposition sites on the study site (used by local males) support this idea. This suggests that males could deposit tadpoles at a more rapid rate. Males should be able to reach high levels of polygyny without exceeding their capacity to perform at least minimal parental care.

If male parental investment is higher than that of females, then I would expect receptive males to be rare. The data on male calling, site tenacity and female-male rejection indicate that this is not the case. The sex role reversal hypotheis also predicts that males will not be highly polygynous, yet males have been seen calling and courting with females when caring for clutches from four different females.

\section{Parental Quality Hypothesis}

Wade \& Arnold (1980) partitioned sexual selection into two components: variance in number of mates and variance in fertility per mate. Variance in fertility per mate is an incomplete description of the second component of sexual selection. To be complete we should include variance in the survivorship and reproductive success of offspring caused by differences in the quality or quantity of parental investment provided by particular mates. The causal factors affecting this variance in mate quality are potentially diverse (e.g. Yasukawa \& Searcy 1982; Petrie 1983). One factor that may affect male quality from a female perspective is polygyny. This is because males may profit by mating polygynously at the expense of some investment per offspring, reducing the male's quality from the female's point of view (Wittenberger 1979). My observations on the behaviour of $D$. auratus suggest that males may profit by mating with many females, because they pay a low cost (sperm and courtship time), and gain the benefit of the opportunity for high offspring production or insurance in case of clutch loss. If male polygyny imposes a cost upon the survival of offspring (e.g. because of reduced deposition site quality), then females should be selective about mating. Once a female has chosen a mate, however, she should attempt to prevent other females from mating with that male (this may not be profitable for all females). Further research is required to evaluate this hypothesis. In particular, the relationship between male polygyny and egg survivorship, and deposition site quality and tadpole survivorship should be investigated to see if male polygyny is negatively correlated with offspring survivorship.

Decline in the quality of male parental care with increasing polygyny does not explain why more than one female should approach a single male. Variance among males in territory quality may create a biased sex ratio on the preferred territories. A comparison of the sex ratio and frequency of female-female aggression on the 1985 and 1986 study sites lends some support to this idea. The study site was located in a drier area in 1985 than it was in 1986, and fewer open pools were available. Population density was lower at the 1985 site, and male territories were more widely dispersed. The ratio of resident males (defined as males who were observed regularly on the study site) to resident females was higher at the 1985 study site $(0.77$ to 0.625 ) and the number of bouts of female aggression per female per $h$ was lower $(0.037-0 \cdot 125)$. This suggests that females may aggregate in areas where water is easily available, whereas males may defend territories for access to females and hence reduce male density.

\section{ACKNOWLEDGMENTS}

I would like to thank my advisors, Arnold Kluge, Nancy Knowlton, A. Stanley Rand and Richard Alexander for advice and support throughout the research. Kentwood Wells, Richard Wrangham, Bernard Crespi, Christopher Petersen and Richard Connor provided valuable coments on the manuscript. Charles Myers provided useful data and advice. Funding for the project was received from The Smithsonian Institution, The Smithsonian Tropical Research Institute, The Explorer's Club, The Sigma Xi Scientific Society and the University of Michigan.

\section{REFERENCES}

Alexander, R. D. \& Borgia, G. 1979. On the origin and basis of the male-female phenomenon. In: Sexual Selection and Reproductive Cumpetition in the Insects (Ed. by M. S. Blum \& N. A. Blum), pp. 417-440. New York: Academic Press.

Altmann, J. 1974. Observational study of behavior: sampling methods. Behaviour, 49, 227-267.

Breder, C. M. 1946. Amphibians and reptiles of the Rio Chucunaque drainage, Darien, Panama, with notes on their life histories and habits. Bull. Am. Mus. Nat. Hist., 86, 375-436. 
Bunnell, P. 1973. Vocalizations in the territorial behavior of the frog, Dendrobates pumilo. Copeia, 1973, 277-284.

Crump, M. 1972. Territoriality and mating behavior in Dendrobates granuliferus (Anura: dendrobatidae). Herpetologica, 28, 195-198.

Duellman, W. E. 1966. Aggressive behavior in dendrobatid frogs. Herpetologica, 22, 217-222.

Dunn, E. R. 1941. Notes on Dendrobates auratus. Copeia, 1941, 88-95.

Eaton, T. 1941. Notes on the life history of Dendrobates auratus. Copeia, 1941, 93-95.

Grow, D. 1977. Reproduction of Dendrobates auratus at the SCZ. Kans. Herpetol. Soc. Newsletter, 17, 9-12.

Halliday, T. R. 1983. The study of mate choice. In: Mate Choice (Ed. by P. P. G. Bateson), pp. 3-29. Cambridge: Cambridge University Press.

Halliday, T. R. \& Verrell, P. A. 1986. Review: sexual selection and body size in amphibians. Herpetol. J, 1, 86-92.

Hrdy, S. B. \& Williams, G. C. 1983. Behavioural biology and the double standard. In: Social Behavior of Female Vertebrates (Ed. by S. K. Wasser), pp. 1-5. New York: Academic Press.

Lumpkin, S. 1983. Female manipulation of male avoidance of cuckoldry behavior in the ring dove. In: Social Behavior of Female Vertebrates (Ed. by S. K. Wasser), pp. 91-112. New York: Academic Press.

Myers, C. W. \& Daly, J. 1976. Preliminary evaluation of skin toxins and vocalizations in taxonomic and evolutionary studies of poison-dart frogs (Dendrobatidae). Bull. Am. Mus. Nat. Hist., 157, 153-262.

Orians, G. H. 1969. On the evolution of mating systems in birds and mammals. Am. Nat., 103, 589-603.

Petrie, M. 1983. Female moorhens compete for small, fat males. Science, N.Y., 220, 413-415.

Petrie, M. 1986. Mating strategies of male and female moorhens (Gallinula chloropus). In: Ecological Aspects of Social Evolution in Birds and Mammals (Ed. by D. I. Rubenstein \& R. W. Wrangham), pp. 43-63. Princeton: Princeton University Press.

Senft, W. 1936. Das Brutgeschaft des Baumsteigerfrosches (Dendrobates auratus Girard) in Gefangenschaft. Zool. Garten, 8, 122-136.

Shine. R. 1979. Sexual selection and sexual dimorphism in the amphibia. Copeia, 1979, 297-306.

Silverstone, P. A. 1973. Observations on the behavior and ecology of a Colombian poison-arrow frog, the Kokoepa (Dendrohates histrionicus Berthold). Herpetologica, 29, 295-301.
Silverstone, P. A. 1975. A revision of the poison-arrow frogs of the genus Dendrobates Wagler. L.A. Nat. Hist. Mus. Sci. Bull., 21, 1-55.

Trivers, R. L. 1972. Parental investment and sexual selection. In: Sexual Selection and the Descent of Man 1871-1971 (Ed. by B. Campbell), pp. 136-179. Chicago: Aldine-Atherton.

Wade, M. J. \& Arnold, S. J. 1980. The intensity of sexual selection in relation to male sexual behavior, female choice, and sperm precedence. Anim. Behav., 28, 446461.

Wells, K. D. 1978. Courtship and parental behavior in a Panamanian poison-arrow frog (Dendrobates auratus). Herpetologica, 34, 148-155.

Wells, K. D. 1980. Behavioural ecology and social organization of a dendrobatid frog (Colostethus inguinalis). Behav. Ecol. Sociobiol, 60, 199-209.

Wells, K. D. 1981. Parental behavior of male and female frogs. In: Natural Selection and Social Behavior: Recent Research and New Theory (Ed. by R. D. Alexander \& D. Tinkle), pp. 184-197. Newton, Massachusetts: Chiron Press.

Weygoldt, P. 1980. Complex brood care and reproductive behaviour in captive poison-arrow frogs, Dendrobates pumilio O. Schmidt. Behav. Ecol. Sociobiol., 7, 329-332.

Williams, G. C. 1966. Adaptation and Natural Selection. Princeton: Princeton University Press.

Wittenberger, J. F. 1979. The evolution of mating systems in birds and mammals. In: Handbook of Behavioral Neurobiology, Vol. 3: Social Behavior and Communication (Ed. by P. Marler \& J. G. Vandenburg), pp. 271 ... 349. New York: Plenum Press.

Yasukawa, K. \& Searcy, W. A. 1982. Aggression in female red-winged blackbirds: a strategy to insure male parental investment. Behav. Ecol. Sociobiol., 8, 186194.

Zimmermann, H. 1974. Die Aufzucht des Goldbaumsteigers, Dendrobates auratus. Aquarien Magazin, 12, $526-531$.

Zimmermann, H. \& Zimmermann, E. 1981. Sozialverhalten, Fortpflanzengsverhalten und Zucht der farberfrosche Dendrobates histrionicus und D. lehmanni sowie einiger anderer Dendrobatiden. Z. Kolner Zoo, 24, 83. 99.

(Received I January 1988; revised 13 June 1988; MS. number: A5122) 